\title{
Conceptual Models of Treatment in Depressed Hispanic Patients
}

\author{
Alison Karasz, PbD \\ Liza Watkins, MA
}

Department of Family Medicine, Albert Einstein College of Medicine, Bronx, NY

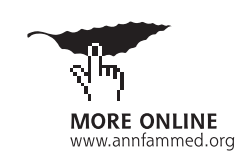

Conflicts of interest: none reported

\section{CORRESPONDING AUTHOR}

Alison Karasz, PhD

Department of Family Medicine

Albert Einstein College of Medicine

3544 Jerome Avenue

Bronx, NY 10467

akkarasz@montefiore.org

\begin{abstract}
PURPOSE Though patient variables are likely to play an important role in the undertreatment of depression, little is known of patients' perceptions of standard depression treatments. In an effort to understand their perspective, we investigated depressed Hispanic patients' perceptions of primary care treatments and the specific benefits associated with them.
\end{abstract}

METHODS We undertook semistructured interviews with 121 depressed Hispanic medical patients waiting for their appointments. We developed and implemented a coding scheme using standard iterative procedures.

RESULTS More than one half of the patients viewed physician consultation and medication as helpful. Almost all patients considered psychotherapy to be helpful. Supportive talk was the most commonly mentioned specific benefit of physician consultation. The most common benefit of medication was its anxiolytic, sedative effect; energizing effects were less common. The most common benefits associated with psychotherapy included support, advice, and catharsis. Patients currently taking medication for depression had a more favorable view of pharmacological treatment; differences by language of interview were noted.

CONCLUSIONS Patients' perceptions of the specific efficacies of depression treatment did not match priorities implicit in current treatment guidelines. Such perceptions may play a key role in shaping patients' decisions to initiate and maintain treatment.

Ann Fam Med 2006,4:527-533. DOI: 10.1370/afm.579.

\section{INTRODUCTION}

$\mathrm{D}$ epression is one of the most prevalent problems in primary care settings. ${ }^{1,2}$ Current guidelines for the treatment of depression in primary care settings emphasize physician diagnosis and the provision of technical, especially pharmacological, treatments; but most depressed patients in primary care settings do not receive guideline-concordant care. ${ }^{3.7}$ Undertreatment is especially common among ethnic minority patients..$^{8-11}$

To date, most studies investigating these issues have either examined the expertise or sensitivity of the physician in diagnosing and treating depression ${ }^{12-15}$ or assessed interventions designed to address physician behavior. ${ }^{16-18}$ Though these approaches are useful, they downplay the active role of the patient in managing depression. Yet studies investigating barriers to treatment from the physician's perspective find that patient variables are a major factor in the decision not to diagnose or treat. ${ }^{19,20}$

In general, there has been little study of primary care patients' conceptual models of depression and its treatment. ${ }^{21}$ Survey studies of health beliefs about depression in the general population suggest that many people conceptualize depression in terms that differ sharply from contemporary biopsychiatric models ${ }^{22,23}$ and they have doubts about the efficacy of pharmacological and psychotherapeutic treatments for depression. ${ }^{24}$ Evidence suggests that both ethnic minorities and those of lower socioeconomic status are more likely than white middle-class patients to conceptualize depression as a social or life problem and to find pharmacological treatment unacceptable..$^{25-27}$ 
The data reported in this article were collected as part of a larger study of conceptual models of depression in a group of low-income, unacculturated Hispanic patients. This report examines conceptual representations of the standard treatments available in primary care settings: physician consultation, counseling, and medication. We focused on patients' perceptions of the specific efficacies of these treatments, that is, the precise nature of treatment benefits. We also examined whether treatment experience and acculturation (as indicated by language of interview) influenced patients' perceptions of treatment efficacy.

\section{METHODS}

The study was conducted in 2 primary care health centers in the Bronx, New York. Consecutive patients of self-reported Hispanic ethnicity were approached while they were waiting for their appointments. Patients judged to be cognitively impaired or confused at the time of interview were excluded.

\section{Screening Measure}

After participating in an informed consent process, patients were screened for depression using the Patient Health Questionnaire (PHQ-9), the depression scale from the PRIME-MD Patient Health Questionnaire, in English or Spanish. ${ }^{28,29}$ Patients meeting criteria for major depression or "other depression" (a cardinal symptom plus at least 1 other depressive symptom) were invited to participate in the study.

\section{Perceptions and Experiences of Treatment for Depression Interview}

The first part of the interview included questions about the patient's experiences of medication, counseling, and physician consultation For each type of treatment experienced, patients were asked to describe whether the treatment was "helping." They were then asked to describe the specific benefits of the treatment, or, if the treatment was not helping, to explain why not. In the second part of the interview, patients were asked to describe their general perceptions of depression treatments. The interview guide can be found online as a Supplemental Appendix at: http://www.

\section{annfammed.org/cgi/content/full/4/6/527/DC1).}

The interview took 15 minutes to complete.

Because the interviews took place in examination rooms and were subject to frequent interruption, taping was deemed unfeasible. Interviewers took verbatim notes and transcribed patients' responses immediately following the interview. Interviewers were experienced qualitative interviewers who had received training in verbatim note-taking and transcription.
In addition, we administered a demographics questionnaire. The language of interview was also recorded.

\section{Analysis}

A combination of template and editing approaches was used to develop the coding scheme. ${ }^{30} \mathrm{~A}$ list of themes based on prior research findings was prepared. With the list of themes in hand, the first author read through $50 \%$ of the transcripts. During this initial coding phase, new themes emerged and were added to the list, resulting in a preliminary coding scheme. The second author then coded the entire data set using the coding scheme. Several additional themes emerged at this stage. In a final step, the second author recoded the data set using the revised coding list. Any ambiguous coding decisions were resolved through discussion between the 2 authors.

Once final coding decisions were reached, coding categories were given numeric labels and were entered into SPSS software (version 11, SPSS Inc, Chicago,Ill). Though inferential statistical techniques were deemed inappropriate for a descriptive, non-hypothesis-testing design of this type, simple frequencies were generated to prepare a detailed description of the data. We also performed a subgroup comparison to examine whether perceptions of treatment differed according to (1) whether the participant reported current or previous experience of treatment, and (2) the language of interview.

\section{RESULTS}

\section{The Sample}

Demographic data collected from participants (Table 1) suggests a low-income, relatively unacculturated group.

\begin{tabular}{lcc}
\hline $\begin{array}{l}\text { Table 1. Demographic Characteristics } \\
\text { of Study Sample }\end{array}$ & \\
\hline Characteristic & Range & Mean \\
\hline Age, years & $18-73$ & 44 \\
Education, years & $0-18$ & 10.1 \\
Income, \$ & $0-10,000$ to & $0-10,000$ \\
& $50,000-100,000$ & 15 (5.2) \\
PHQ-9 score (SD) & $6-25$ & - \\
Female, \% & 77 & - \\
Works outside the home, \% & 37 & - \\
Language of interview, \% & & - \\
Spanish & 51 & - \\
English & 49 & - \\
Place of birth, \% & & - \\
Puerto Rico & 33 & - \\
Dominican Republic & 25 & - \\
United States & 30 & \\
Other & 12 & - \\
\hline PHQ-9 = Patient Health Questionnaire, from the PRIME-MD Patient Health \\
Questionnaire.
\end{tabular}


The mean PHQ-9 score was 15, which lies in the moderate to moderately severe range.

\section{Treatment Experiences}

As a group, participants had experience with depression treatment (Table 2). Forty-two percent reported that they had discussed their depression with their physician. Of these, about one half reported receiving advice or counseling from their physicians; medication and referral were less common. Nearly one half were in active treatment for their depression, while an additional one third reported past treatment.

\section{Barriers to Treatment}

Many participants offered information about potential barriers to treatment. The most common problems included financial problems, lack of time, and physical health problems.

"I have no insurance, but I can't pay [a therapist] regardless... I am the only supporter of the house and I'm supporting a lot of people" (Patient 75).

"The social worker used to go to my house but not anymore because my health [insurance] does not pay for it anymore" (Patient 86).

"I have too many things at the same time, too many physical specialists, so I have a lack of time and energy. I have to prioritize and focus" (Patient 35).

Though stigma is commonly considered an important barrier to treatment for depression, ${ }^{19,20,31}$ only 5 mentioned stigma-related themes, such as embarrassment or privacy concerns.

\section{Perceptions of Depression Treatment}

In general, patients were hopeful about treatments available in primary care settings, including physician consultation, medication, and especially psychotherapy/ counseling (Table 3). Self-help strategies, such as problem solving and lay consultation, were also viewed as helpful.

\section{Physician Consultation}

Given the current guidelines' emphasis on the physician diagnosis as a necessary prerequisite to treatment, we were interested to know how patients thought physicians would be able to help them with depression. The most commonly mentioned help that physicians could offer was supportive talk: advice, guidance, and comfort (Table 4).

"I can talk to my doctor about my problems. She gives me guidance. I also can e-mail her, and we call each other on the phone" (Patient 93).

"Even though they are not for that, when I tell him how I feel, he tells me what I could eat, [what medicine I could] take to feel better. I trust him" (Patient 118).

"Yes, I would get advice, guidance on what is good and bad. The doctors would tell me what I must think, not only about my problems" (Patient 24).

A much smaller group said physicians were helpful because they offered medication, mental health referrals, or treatment for physical problems causing depression. Most patients who had been helped by their physicians described multiple healing experiences:

"The migraines make my depression worse because I lay down in my room in the dark and start thinking about my life. My doctor listens to me. She prescribes

Table 2. Treatment Experiences of Study Patients $(n=121)$

\begin{tabular}{lc}
\hline Experience & No. (\%) \\
\hline Currently in treatment & $51(42)$ \\
Received treatment in the past (not currently & $40(33)$ \\
in treatment) & $16(13)$ \\
Took medications in past & $34(26)$ \\
Received therapy in past & $51(42)$ \\
Has discussed depression with physician & $50(42)$ \\
Received intervention from physician & $18(15)$ \\
Received prescription & $30(25)$ \\
Received counseling & $19(16)$ \\
Received referral from physician &
\end{tabular}

Table 3. Patients' Perceptions of the Helpfulness of Treatment $(n=121)$

\begin{tabular}{lc}
\hline Perception of Treatment & No. (\%) \\
\hline Medication & $65(54)$ \\
Would be helpful & $17(19)$ \\
Maybe or not sure & \\
Therapy or counseling & $105(88)$ \\
$\quad$ Would be helpful & $9(8)$ \\
Maybe or not sure & $75(62)$ \\
Discussing depression with my physician & $10(8.4)$ \\
$\quad$ Would be helpful & \\
Maybe or not sure & $51(42)$ \\
Self-help strategies that would help & $57(48)$ \\
Taking care of current problems in living & \\
Talking with people more about my feelings &
\end{tabular}

Table 4. Perceived Benefits of Physician Consultation Among Patients Who Thought Consultation Would be Helpful, or Were Not Sure $(n=85)$

\begin{tabular}{lc}
\hline Perceived Benefit & No. (\%) \\
\hline Physicians help because they give advice or guidance & $43(50)$ \\
Physicians help because they talk to me & $12(14)$ \\
Physicians help because they offer antidepressant & $27(32)$ \\
$\quad \begin{array}{l}\text { medication } \\
\text { Physicians help by giving mental health referrals }\end{array}$ & $22(26)$ \\
$\begin{array}{l}\text { Physicians help with physical problems that cause } \\
\text { depression }\end{array}$ & $12(14)$ \\
\hline
\end{tabular}


medication for my migraines and she believes in $\mathrm{me}^{\prime \prime}$ (Patient 101).

"When I see him, he tries to help me. He referred me to a psychiatrist. He encourages and advises me. He asked if I had spoken to a priest" (Patient 34).

Among participants who said that physicians were not helpful, about one half said their doctors were concerned only with physical problems; others noted that the doctor could not change their basic life situation:

"I don't show my problems [to my doctor]. I deal with them as they come, because they'll always keep on coming. Nothing can change the fact that my mother passed away" (Patient 21).

"[My depression] depends on [my] school situation. I keep things private from my doctor. She really doesn't understand. She [focuses on] the physical" (Patient 4).

"My sadness comes from problems at home with my brother. The doctor cannot help with that. He can only help with health problems" (Patient 111).

\section{Specific Efficacies of Medication}

We classified responses into 3 categories (Table 5)

The first category was sedative effects (calming, relaxing, helping with sleep); the second was tonic effects (energizing, improving productivity, helping with concentration); the third was euthymic effects (responses indicating a reduction in sadness or improvement in mood). Nearly one half of participants indicated that medication would have helpful sedative effects. Most of these emphasized that medication could help them calm down in the face of real-life problems.

"Medicine could help ... me to relax when I'm down and worrying about so many things" (Patient 102).

"Medications help me to sleep because I don't think about my problems" (Patient 72).

A much smaller group suggested that medication could have tonic effects, helping them to have more energy, concentrate, or get more done.

"It makes me feel normal, stabilized. I gain energy and at night it helps me sleep" (Patient 101).

"Prozac gives me energy and helps me get out of bed" (Patient 105).

Three persons mentioned that medication could help you stop crying, but no other specific euthymic effects were described.

"It maintains me and I don't cry as often" (Patient 99).

\section{Problems With Medication}

Side effects have often been proposed as a major reason that patients refuse or drop out of treament. ${ }^{4,5}$ In this study, side effect concerns were less common than doubts about treatment efficacy. Of the 38 patients who mentioned side effects, the most common concern was that antidepressants made a person feel sedated:
Table 5. Perceived Efficacies of Medication, Among Patients Who Said Medication Would be Helpful, or Were Not Sure $(n=83)$

\begin{tabular}{lc}
\hline Efficacy & No. (\%) \\
\hline Sedative effects (calming, relaxing, helping with sleep) & $47(56)$ \\
$\begin{array}{l}\text { Tonic (energizing, helping person work more, concen- } \\
\text { trate better) }\end{array}$ & $18(21)$ \\
Mood improvement ("helps you stop crying") & $3(4)$ \\
\hline
\end{tabular}

Table 6. Perceived Efficacies of Psychotherapyl Counseling, Among Those Who Thought It Would be Helpful, or Were Not Sure $(n=114)$

\begin{tabular}{lc}
\hline Efficacy & No. (\%) \\
\hline Speaking intimately in a supportive setting & $72(63)$ \\
Getting things off your chest & $64(56)$ \\
Giving advice or helping to make decisions & $52(46)$ \\
Resolving past issues & $6(5)$ \\
Changing your behavior & $13(11)$ \\
Changing your thinking & $19(17)$ \\
\hline
\end{tabular}

"They kind of just get you sleepy and drug you out. They make you worse. You feel like you are in another world" (Patient 59).

"The medication just put me to sleep. It didn't help because it made me more lazy and that just made things worse" (Patient 117).

A smaller group expressed concerns about addiction.

"I have a friend taking meds. They help to relax her sometimes, but she is now an addict and feels worse" (Patient 32).

"Pills help momentarily, but the truth is still there. People become dependent on pills for their problems" (Patient 80).

A common reason for dissatisfaction with medication was the belief that it did not work because it did not address the interpersonal or social problems causing the depression:

"I don't have a chemical imbalance. I feel this way when something is happening in my life" (Patient 121).

"Sometimes it's not a medical problem, the depression is caused by personal problems that need to be solved. I tried [pills] before and they did not help" (Patient 106).

"No, this is not for medicine. This is an internal worry that has to pass.... My main problem is my son" (Patient 40).

\section{Psychotherapy and Counseling}

As noted, the great majority of participants asserted that their depression could be helped by psychotherapy or counseling (Table 6). When we asked about 
specific efficacies of therapy, we found that speaking intimately in a supportive setting was most commonly considered to be helpful for depression.

"Yes, many times a person has blocks of speaking about personal things because they don't trust a friend. You can talk and feel better to talk about what is inside. Their friendly words can make you feel better" (Patient 52).

Catharsis - getting things off your chest—was a commonly mentioned specific efficacy:

"You can speak to the counselor about what is happening and use them as an outlet-if not, you feel you're going to explode" (Patient 106).

"By seeing a counselor, you talk about whatever is on your mind. You get rid of everything you don't want to tell your family" (Patient 46).

Advice and guidance were also frequently mentioned

"Because that is their field, they know how to intervene in a crisis. They set plans and goals to achieve a ... long-term focus on the problem" (Patient 97).

"They can help by giving advice and being able to help someone think in a positive way, to think and feel better. It would help anybody. Advice is good to anybody" (Patient 36).

In addition to these benefits, a much smaller group suggested efficacies related to specific psychotherapeutic paradigms, such as increased self-awareness or insight, or cognitive-behavioral change.

"They can help me with stress because I am having problems with my partner. I take out my stress on him-I even caused our wedding to be called off. I need to learn to deal with it better... They can tell me how to approach the problem and what to do in certain situations" (Patient 102).

Though somatization is often proposed as a barrier to treatment in primary care, ${ }^{1,31}$ only 6 patients felt that therapy would not be helpful because theirs was a physical problem.

"My feeling of weakness is not a psychological problem, it's more due to my recent surgery" (Patient 112).

\section{Subgroup Analysis}

In the next phase of the analysis, we examined whether experience of treatment, medication, or counseling and therapy affected perceptions of efficacy. Of the 38 currently taking medication, unsurprisingly, $79 \%$ felt it to be helpful, a considerably higher proportion than the overall group. Perceptions of treatment efficacies were similar to those of the overall sample: patients were more than twice as likely to ascribe sedative, than energizing, effects, and there was little mention of euthymic effects. Participants currently in psychotherapy did not differ in perceptions of general efficacy or specific efficacies from the overall sample.
We next examined those who reported previous experience with treatment. Perceptions of general and specific efficacy resembled those of the larger sample.

\section{Language}

Based on the notion that language of interview is a proxy for acculturation, we divided the sample into English and Spanish speakers and examined their treatment experiences and conceptual models separately. Nearly one half (47\%) of Spanish speakers were currently in treatment as opposed to $34 \%$ of English speakers. Spanish and English speakers did not differ in perceptions of the efficacy of physician consultation and psychotherapy or counseling. When we looked at perceptions of pharmacological efficacy, however, one major difference did emerge. Though English and Spanish speakers were equal in their perception that pharmacotherapy would have sedative effects $(40 \%$ vs $37 \%)$, English speakers were twice as likely as Spanish speakers to believe that medication would have tonic effects, making them more active, energetic, or able to concentrate ( $21 \%$ vs $10 \%$, respectively).

\section{DISCUSSION}

This exploratory study used qualitative methods to elicit experiences and perceptions of treatment in a group of low-income Hispanic medical patients with a diagnosis of depression. Most were either in treatment or had been in treatment in the past. The majority thought their primary care physician could be helpful in treating their depression. Three quarters thought medication could be helpful or were not sure. A larger proportion was optimistic about the benefits of counseling, reflecting other findings in the research literature. ${ }^{32}$ Participants currently in treatment were more likely to view it as efficacious.

This study probed further than most reported in the literature in that it investigated, not only the types of treatments that were acceptable to participants, but also the specific efficacies associated with these treatments. In describing the benefits of physician consultation, patients more often described the benefits of conversation than those of medication prescription and mental health referral. The most common specific efficacy associated with medication was its sedative, anxiolytic effects. Tonic, energizing effects were experienced or anticipated by relatively few. There was little mention of euthymic effects. For psychotherapy, nonspecific effects related to the benefits of talking, such as comfort, advice, and catharsis, were the most common perceived treatments.

These findings contrast with current guidelines for depression treatment, which derive from a disease 
model of depression that emphasizes diagnosis and the provision of technical treatments. Our participants' emphasis on supportive talk with the physician as an effective treatment for depression suggests a possible gap between patients' priorities and those implied in the guidelines. Almost nothing is known about the therapeutic effects associated with physicians' conversations with depressed patients - or indeed, about the actual content of these conversations. Results of the present study suggest that they warrant further investigation.

Our findings also contrast with representations of specific efficacies in the popular media and professional literature. For example, direct-to-consumer advertising campaigns tend to emphasize the euthymic effects of antidepressants, exemplified by the famous Prozac advertisement: a small tree receives a drenching shower on the first page but basks in sunshine on the next. A common theme in mainstream representations of antidepressants is that they enhance productivity and sociability. Peter Kramer, in Listening to Prozac, was one of the first to claim that some classes of antidepressants make people "better than well." ${ }^{33}$ These themes are rarely mentioned in our participants' reports.

Findings also contrast with the claims of specific psychotherapeutic theories. Practitioners within different theoretical paradigms, such as psychodynamic or cognitive-behavioral therapy, tend to emphasize different efficacies, ranging from insight, to behavior change, to problem solving. ${ }^{34,35}$ Taken as a whole, however, outcome research suggests that the effectiveness of most therapies derive from nonspecific elements, such as interpersonal support, empathy, and the activation of hope. ${ }^{34}$ These nonspecific effects were reflected in participants' perceptions of treatment efficacies for psychotherapy, which emphasized support, advice, and catharsis. Such nonspecific aspects of therapeutic talk are part of a tradition of verbal healing that long precedes the development of modern psychotherapeutic paradigms. ${ }^{36}$

Because concepts of specific efficacy did not appear to differ between patients in treatment and those not in treatment, our results cannot be explained by patients' lack of treatment experience. One possible explanation for patients' emphasis on anxiolytic effects is that a large proportion was taking a tricyclic antidepressant rather than a selective serotonin reuptake inhibitor (SSRI). Though it is often assumed that the tricyclic antidepressants are more effective anxiolytics than the SSRIs, recent reviews have found no differences between the 2 classes of medication. ${ }^{37,38}$

Another possibility is that the experience of specific treatment efficacies may be shaped by cultural factors. In the present analysis, we found that Spanish-speaking participants were only one half as likely as English speakers to perceive tonic, energizing effects of medica- tion. In the absence of comparative, cross-cultural data, it is difficult to gauge the extent of culture's influence on perceptions of treatment efficacies. One interesting possibility, however, is that expected treatment efficacies reflect the values of a particular cultural milieu. In the present case, the focus on activation among English speakers may reflect middle-class American cultural emphases on productivity and performance.

Appreciation of the widespread problem of undertreatment in depression has led to a new interest in the influences of patient preferences on adherence and dropout. ${ }^{39-41}$ The results of our preliminary study suggest that perceptions of specific efficacies may represent an important extension of the concept of treatment preferences. When patients do not find the specific benefits they are looking for-whether sedative effects or emotional support - they may withdraw from treatment regardless of their initial treatment preference. More research is needed to understand these issues.

More research is needed, too, on the actual experiences of patients currently in treatment for depression. Since depression treatment is empirical, directed at symptoms rather than underlying disease process, patients' perceptions of efficacy should be an important guide to understanding how such treatment actually helps. As research on treatment for depression shifts from randomized-controlled trials evaluating efficacy toward studies in real-life clinical settings that assess effectiveness, we must be sure that we have listened enough to depressed patients to know how to ask the right questions.

To read or post commentaries in response to this article, see it online at http://www.annfammed.org/cgi/content/full/4/6/527.

Key words: Ethnic groups; mental health; depression; antidepressants; psychotherapy; physician-patient relations; conceptual models; primary care

Submitted November 3, 2005; submitted, revised, February 11, 2006; accepted February 27, 2006.

Funding support: This study was supported by a grant from the National Institute of Mental Health: 1-K-23 MH067141-01A1.

\section{References}

1. Katon W, Kleinman A, Rosen G. Depression and somatization: a review. Part I. Am J Med. 1982;72:127-135.

2. Angst J. Depression and anxiety: a review of studies in the community and in primary health care. In: Sartorius N, Goldberg D, de Girolamo G, et al, eds. Psychological Disorders in General Medical Setting. Toronto, Ontario: Hans Huber Publishers; 1990:60-68.

3. McQuaid JR, Stein MB, Laffaye C, McCahill ME. Depression in a primary care clinic: the prevalence and impact of an unrecognized disorder. J Affect Disord. 1999;55:1-10.

4. Katon W, von Korff M, Lin E, Bush T, Ormel J. Adequacy and duration of antidepressant treatment in primary care. Med Care. 1992;30:67-76. 
5. Lin EH, Von Korff M, Katon W, et al. The role of the primary care physician in patients' adherence to antidepressant therapy. Med Care. 1995;33:67-74.

6. Simon GE, Von Korff M, Rutter CM, Peterson DA. Treatment process and outcomes for managed care patients receiving new antidepressant prescriptions from psychiatrists and primary care physicians. Arch Gen Psychiatry. 2001;58:395-401.

7. Wells KB, Katon W, Rogers B, Camp P. Use of minor tranquilizers and antidepressant medications by depressed outpatients: results from the medical outcomes study. Am J Psychiatry. 1994;151:694-700.

8. Chung H, Teresi J, Guarnaccia P, et al. Depressive symptoms and psychiatric distress in low income Asian and Latino primary care patients: prevalence and recognition. Community Ment Health J. 2003:39:33-46

9. Commander MJ, Dharan SP, Odell SM, Surtees PG. Access to mental health care in an inner-city health district. II: Association with demographic factors. Br J Psychiatry. 1997;170:317-320.

10. Commander MJ, Odell SM, Surtees PG, Sashidharan SP. Care pathways for south Asian and white people with depressive and anxiety disorders in the community. Soc Psychiatry Psychiatr Epidemiol. 2004;39:259-264.

11. Wells K, Hough R, Golding J, Burnam A, Karno M. Which Mexican Americans under utilise health services? Am J Psychiatry. 1987; 144:916-922.

12. Badger LW, deGruy FV, Hartman J, et al. Psychosocial interest, medical interviews, and the recognition of depression. Arch Fam Med. 1994;3:899-907.

13. Badger LW, deGruy FV, Hartman J, et al. Patient presentation interview content, and the detection of depression by primary care physicians. Psychosom Med. 1994;56:128-135.

14. Carney PA, Eliassen MS, Wolford GL, et al. How physician communication influences recognition of depression in primary care. J Fam Pract. 1999;48:958-964.

15. Robbins JM, Kirmayer LJ, Cathebras P, Yaffe MJ, Dworkind M. Physician characteristics and the recognition of depression and anxiety in primary care. Med Care. 1994;32:795-812.

16. Dowrick C. Does testing for depression influence diagnosis or management by general practitioners? Fam Pract. 1995;12:461-465.

17. Williams JW, Jr., Mulrow CD, Kroenke K, et al. Case-finding for depression in primary care: a randomized trial. Am J Med. 1999;106:36-43.

18. Callahan CM, Dittus RS, Tierney WM. Primary care physicians' medical decision making for late-life depression. J Gen Intern Med. $1996 ; 11: 218-225$

19. Susman JL, Crabtree BF, Essink G. Depression in rural family practice. Easy to recognize, difficult to diagnose. Arch Fam Med. 1995:4:427-431.

20. Nutting PA, Rost K, Dickinson M, et al. Barriers to initiating depression treatment in primary care practice. J Gen Intern Med. 2002;17:103-111.

21. Brown C, Dunbar-Jacob J, Palenchar DR, et al. Primary care patients' personal illness models for depression: a preliminary investigation. Fam Pract. 2001;18:314-320.

22. Lauber C, Nordt C, Falcato L, Rossler W. Do people recognise mental illness? Factors influencing mental health literacy. Eur Arch Psychiatry Clin Neurosci. 2003;253:248-251.
23. Jorm AF, Christensen H, Medway J, et al. Public belief systems about the helpfulness of interventions for depression: associations with history of depression and professional help-seeking. Soc Psychiatry Psychiatr Epidemiol. 2000;35:211-219.

24. Lauber C, Nordt C, Falcato L, Rossler W. Lay recommendations on how to treat mental disorders. Soc Psychiatry Psychiatr Epidemiol. 2001;36:553-556

25. Guarnaccia PJ, Farias P. The social meanings of nervios: a case study of a Central American woman. Soc Sci Med. 1988;26:1223-1231.

26. Jenkins JH, Cofresi $\mathrm{N}$. The sociosomatic course of depression and trauma: a cultural analysis of suffering and resilience in the life of a Puerto Rican woman [see comment]. Psychosom Med. 1998;60:439-447.

27. Karasz A, Sacajiu G, Garcia N. Conceptual models of psychological distress among low-income patients in an inner-city primary care clinic. J Gen Intern Med. 2003;18:475-477.

28. Spitzer RL, Kroenke K, Williams JB. Validation and utility of a selfreport version of PRIME-MD: the PHQ primary care study. Primary Care Evaluation of Mental Disorders. Patient Health Questionnaire. JAMA. 1999;282:1737-1744.

29. Diez-Quevedo C, Rangil T, Sanchez-Planell L, Kroenke K, Spitzer RL. Validation and utility of the patient health questionnaire in diagnos ing mental disorders in 1003 general hospital Spanish inpatients. Psychosom Med. 2001;63:679-686.

30. Miller W, Crabtree B. Clinical research: a multimethod typology and qualitative roadmap. In: Crabtree B, Miller W, eds. Doing Qualitative Research. Thousand Oaks, Calif: Sage Publications; 1999:3-32.

31. Goldman LS, Nielsen NH, Champion HC. Awareness, diagnosis, and treatment of depression. J Gen Intern Med. 1999;14:569-580.

32. Priest RG, Vize C, Roberts A, Roberts M, Tylee A. Lay people's attitudes to treatment of depression: results of opinion poll for Defeat Depression Campaign just before its launch. BMJ. 1996;313:858-859.

33. Kramer PD. Listening to Prozac. Revised ed. New York: Penguin Books; 1997.

34. Luborsky L, Singer B. Comparative studies of psychotherapies. Is it true that "everyone has one and all must have prizes"? Arch Gen Psychiatry. 1975;32:995-1008.

35. Rosenzweig S. Some implicit common factors in diverse methods in psychotherapy. Am J Orthopsychiatry. 1936;6:412-415.

36. Jackson S. Care of the Psyche: A History of Psychological Healing. New Haven, Conn: Yale University Press; 1999.

37. Montgomery SA, Judge R. Treatment of depression with associated anxiety: comparisons of tricyclic antidepressants and selective serotonin reuptake inhibitors. Acta Psychiatr Scand Suppl. 2000;403:9-16

38. Tollefson GD, Holman SL, Sayler ME, Potvin JH. Fluoxetine, placebo, and tricyclic antidepressants in major depression with and without anxious features. J Clin Psychiatry. 1994;55:50-59.

39. Cassano P, Fava M. Tolerability issues during long-term treatment with antidepressants. Ann Clin Psychiatry. 2004;16:15-25.

40. Aikens JE, Nease DE, Jr., Nau DP, Klinkman MS, Schwenk TL. Adherence to maintenance-phase antidepressant medication as a function of patient beliefs about medication. Ann Fam Med. 2005;3:23-30.

41. Pyne JM, Rost KM, Farahati F, et al. One size fits some: the impact of patient treatment attitudes on the cost-effectiveness of a depression primary-care intervention. Psychol Med. 2005;35:839-854. 